\title{
Effects of green tea extract on overweight and obese women with high levels of low density-lipoprotein-cholesterol (LDL-C): a randomised, double-blind, and cross-over placebo-controlled clinical trial
}

Lin-Huang Huang ${ }^{1 *}$ (D), Chia-Yu Liu' ${ }^{1,2}$, Li-Yu Wang $^{2}$, Chien-Jung Huang ${ }^{2,3}$ and Chung-Hua Hsu ${ }^{1,2}$

\begin{abstract}
Background: This study aims to examine the effects of green tea extract (GTE) supplement on overweight and obese women with high levels of low density lipoprotein-cholesterol (LDL-C).

Methods: The randomized, double-blind, crossover and placebo-controlled clinical trial was conducted from August 2012 to December 2013. Seventy-three out of 90 subjects aged between 18 and 65 years, with body mass index (BMI) $\geq 27 \mathrm{~kg} / \mathrm{m}^{2}$ and LDL-C $\geq 130 \mathrm{mg} / \mathrm{dl}$ were included in the analysis. The subjects were randomly divided into Groups $A$ and B. Group A received GTE supplement treatment for the first 6 weeks, while Group B received placebo daily. After 6 weeks of treatment and 14 days of washout period, Group A switched to placebo and Group B switched to GTE treatment for 6 weeks. The reduction of LDL-C level between treatments was assessed as the outcome. Additionally, anthropometric measurements, plasma lipoproteins and hormone peptides of both groups were measure at the beginning of weeks 6,8 , and 14 after treatment.

Results: Subjects treated with GTE $(n=73)$ for 6 weeks showed significant differences, with $4.8 \%(p=0.048)$ reduction in LDL-C and $25.7 \%(p=0.046)$ increase in leptin. However, there was no statistical difference in the levels of total cholesterol, triglyceride and high density lipoprotein between the GTE and placebo groups after treatments.

Conclusions: This study shows that green tea extract effectively increases leptin and reduces LDL in overweight and obese women after 6 weeks of treatment even though there were no significant changes in other biochemical markers related to overweight.
\end{abstract}

Trial registration: This clinical trial is registered with ClinicalTrials.gov: NCT02116517 on 17 April 2014. Retrospectively registered. The first patient enrolled in October 2012 and the study was completed December 2013.

Keywords: Obesity, Green tea extract, Epigallocatechin gallant, EGCG, Hyperlipidemia, LDL-C, Low density lipoprotein, Leptin

\footnotetext{
* Correspondence: yg1236@gmail.com

${ }^{1}$ Institute of Traditional Medicine, National Yang-Ming University, No. 155

Section 2, Linong St, Beitou District, Taipei City, Taiwan112

Full list of author information is available at the end of the article
}

(c) The Author(s). 2018 Open Access This article is distributed under the terms of the Creative Commons Attribution 4.0 International License (http://creativecommons.org/licenses/by/4.0/), which permits unrestricted use, distribution, and reproduction in any medium, provided you give appropriate credit to the original author(s) and the source, provide a link to the Creative Commons license, and indicate if changes were made. The Creative Commons Public Domain Dedication waiver (http://creativecommons.org/publicdomain/zero/1.0/) applies to the data made available in this article, unless otherwise stated. 


\section{Background}

Obesity is one of the leading preventable causes of death in the world. Due to its high prevalence rate worldwide, it was classified as a chronic disease in 1995 by the World Health Organization (WHO) [1, 2]. Obesity and high levels of low density lipoprotein-cholesterol (LDL-C) are the main causes leading to cardiovascular disease (CVD) [3], whereas high level of LDL-C is considered as an important risk factor for CVD in obese individual. It is known that CVD morbidity is one of the major causes of global deaths [4]. Hyperlipidemia is also one of the key risk factors for CVD [5]. Numerous studies have found that obesity puts a person at an increased risk for diseases such as hyperlipidemia and CVD [6]. However, some drugs used to reduce LDL-C levels and treat hyperlipidemia [7-11] have been reported to have negative side effects on liver function [11-13]. It is therefore, imperative to explore alternatives such as herbal medicine to lower LDL-C that possesses fewer side effects.

Green tea (Camellia sinensis; GT), a very popular drink in the world [14], has been studied extensively for its beneficial effects on preventing cardiovascular diseases [12] and metabolic diseases [15-18]. Green tea extract (GTE) was reported to counter insulin resistance and favorably alter fat metabolism [19]. Other benefits of green tea include being antioxidant, anti-hypertensive, and anti-inflammatory. In particular, it has been shown to increase energy expenditure [20] and enhance metabolic rate and fat-burning ability [21], so as to relieve the hyperlipidemia and hyperglycemia, and had been used for slimming or obesity control for a long time [22-27]. Polyphenols of green tea are considered as the main constitutions attributed to anti-lipid effects of green tea. The four major flavonoids, epicatechin (EC), epigallocatechin (EGC), epicatechingallate (ECG), and epigallocatechin gallate (EGCG), are the catechins among all the bioactive polyphenols. The efficacy of green tea may be attributed to the presence of catechin polyphenols, and it has been suggested that EGCG could be responsible for the various health effects associated with green tea [28].

Metabolic syndrome is an escalating global epidemic. Obesity is a metabolic disorder characterized by excess fat accumulation in the body. Due to unsafe medicines and inevitable side effects, reducing metabolic disorders is burdened with serious problems. Medicinal plants and derived products are becoming increasingly popular as natural alternatives to synthetic drugs for the treatment of hypercholesterolemia and hypertriglyceridemia in modern society. Obesity is highly associated with the development of hyperlipidemia and non-alcoholic fatty liver disease. Many natural or plant-derived compounds, including GTE and EGCG have been researched to understand their effects on weight control $[19,29]$, or hyperlipidemia [30, 31]. However, little is known about the extent to which
GTE can affect obese women with high LDL-C levels. Recently, Rocha et al. reported that GTE ameliorates the metabolic dysfunction of adipose tissue, that is induced by obesity, through the AMP-activated protein kinase (AMPK)-regulated pathway [32].

Men and women with the same degree of overweight show differences in that men have higher triglyceride, fasting glucose, insulin levels as well as blood pressure. There is also a difference in the distribution of adipose tissue, with women having more body fat [33]. Hence gender was stratified in this study.

We hypothesized that GTE would help in lowering LDL-C levels in overweight and obese women, and, therefore, investigated the anti-obesity effect of GTE on these women by focusing on both the biochemical and physiological responses in a randomized, cross-over clinical trial.

\section{Methods}

\section{Study design and participants}

This trial was conducted from August 2012 to December 2013 in Taipei City Hospital, Taiwan. Among 236 registered obese women screened at our outpatient clinic, a total of 90 participants were enrolled. Inclusion criteria for participants included the following: ethnically Taiwanese, female, age between 18 and 65 years, BMI $\geq 27 \mathrm{~kg} / \mathrm{m}^{2}$, and $\mathrm{LDL}-\mathrm{C} \geq 130 \mathrm{mg} / \mathrm{dl}$. Exclusion criteria included any of the following: (1) aminotransferases aspartate or aminotransferases alanine $>80 \mathrm{IU} / \mathrm{L}$ and serum creatinine $>1.8 \mathrm{mg} /$ $\mathrm{dl}$, (2) lactating or pregnant women, (3) a prior history of heart failure, acute myocardial infarct, stroke or heavy injuries, and (4) any other conditions not suitable for trial as evaluated by the physician-in-charge. Authors of this study had access to information that could identify individuals after data collection and all patients gave written consent by signing a consent form.

The participants were randomly divided into Group A and B. In the first stage, Group A received GTE supplement treatment while Group B received placebo daily. The second stage started after 14 days of washout, where Group A was switched to placebo and Group B to GTE for 6 weeks (Fig. 1). The protocol was approved by the $\mathrm{Hu}$ man Ethics Committee of the hospital. The patients were instructed to maintain an isocaloric diet and in accordance to their previous eating habit during the study period. Every subject had to come to the hospital once a week for blood sampling and for us to assess if they adhered to the prescribed GTE or placebo. All subjects were free to withdraw at any time during the course of the study.

\section{Randomization and blindness}

All participants were randomly assigned to either placebo or GTE treatment. A random number between 0.0 and 0.99 was generated by the computer program for each subject. Those given random numbers between 0.0 


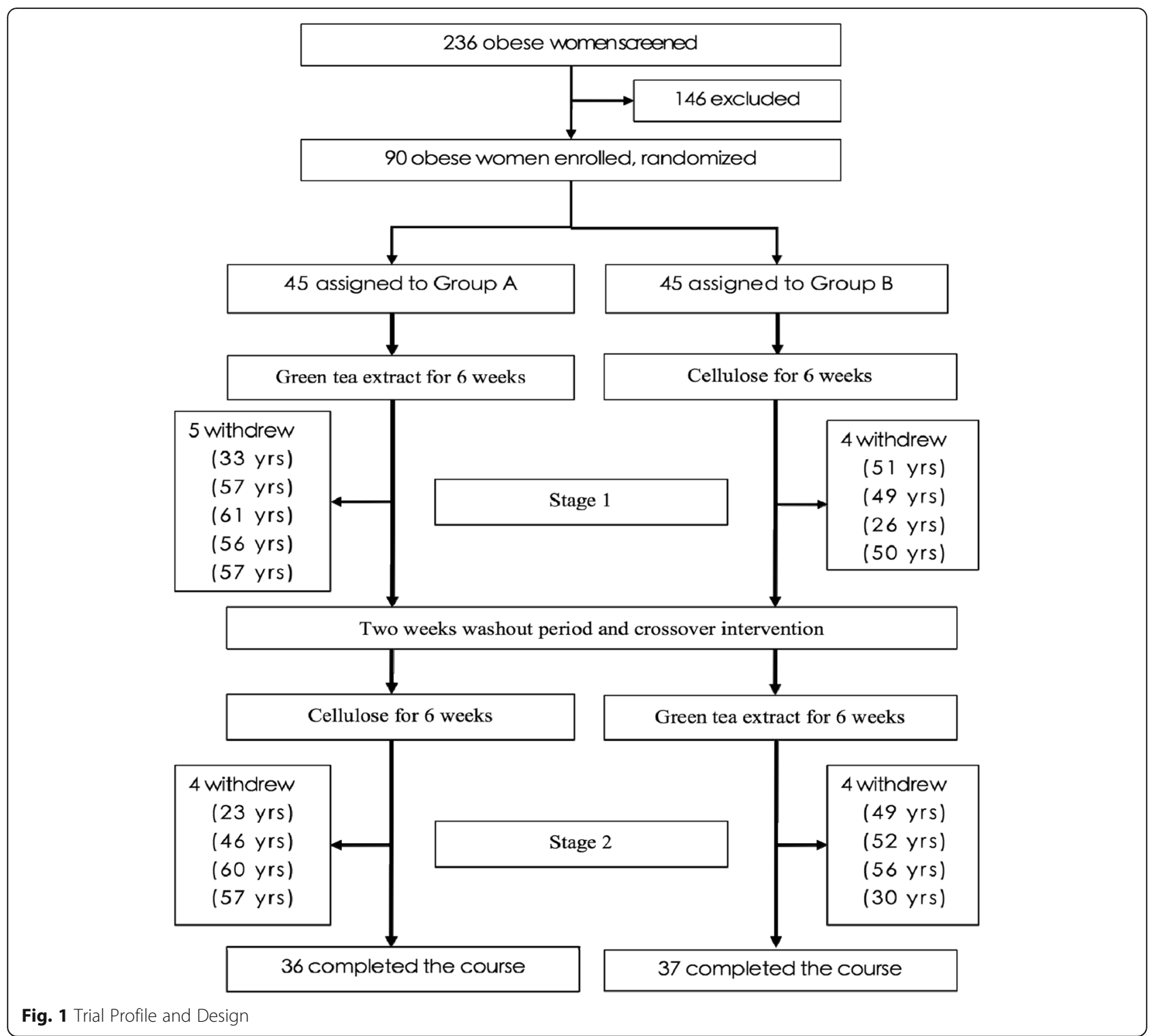

and 0.49 were assigned to the treatment group to receive GTE, while others with numbers between 0.50 and 0.99 were assigned to the placebo group to receive cellulose, during stage 1 . To ensure that the capsules looked and smelled identical, opaque capsules were used to contain either GTE or placebo (cellulose). They were administered to the participants by a research assistant who was also blinded to the contents of the capsules. Characteristics of all the participants at baseline are shown in Table 1.

\section{Preparation of samples and treatment}

The GTE samples, extracted from dried green tea leaves, were procured from the Tea Research and Extension Station, Taiwan. It was manufactured by a standard procedure and came with a certificate of analysis. The control group was given placebo which was pure microcrystalline cellulose. The participants were asked to take one capsule 30 min after meal, three times a day for 6 weeks in each stage. Daily intake of GTE compounds is listed in Table 2, among which EGCG amounted to $856.8 \mathrm{mg}$.

\section{Outcome measurements}

As Table 1 shows, reduction of LDL-C level between two different treatments was used as one of the major outcome measurements. Additionally, plasma lipoproteins such as triglyceride, cholesterol, HDL-C and LDL, as well as hormone peptides of both groups were measured at the baseline, the 6th, 8th and 14th week after treatments. All measurements were made 8-9 h after an overnight fast using standardized methods and were repeated throughout the trial. All the participants had their measurements done with their undergarments and 
Table 1 Characteristics of Participants at Baseline

\begin{tabular}{|c|c|c|c|}
\hline Characteristics & $\begin{array}{l}\text { Group A } \\
n=36 \\
\text { mean (SD) }\end{array}$ & $\begin{array}{l}\text { Group B } \\
n=37 \\
\text { mean (SD) }\end{array}$ & $p$ value \\
\hline \multicolumn{4}{|l|}{ Anthropometric data } \\
\hline Age, years & $53.1(11.2)$ & $56.8(7.9)$ & 0.10 \\
\hline Weight, kg & $70.6(11.4)$ & $67.8(9.1)$ & 0.25 \\
\hline Height, cm & $156.0(4.6)$ & $155.7(5.1)$ & 0.79 \\
\hline Body Mass Index, $\mathrm{kg} / \mathrm{m}^{2}$ & $29.1(4.9)$ & $27.9(3.3)$ & 0.26 \\
\hline Waist Circumference, cm & $89.7(12.4)$ & $86.6(9.5)$ & 0.23 \\
\hline Hip Circumference, cm & $100.8(8.8)$ & $99.5(6.6)$ & 0.48 \\
\hline Waist hip ratio & $0.9(0.1)$ & $0.9(0.1)$ & 0.24 \\
\hline \multicolumn{4}{|l|}{ Biochemical data } \\
\hline Fasting blood sugar, mg/dL & $105.2(23.8)$ & $114.9(49.0)$ & 0.29 \\
\hline Total cholesterol, mg/dL & $218.8(42.4)$ & $229.6(30.3)$ & 0.21 \\
\hline Triglyceride, mg/dL & $147.4(57.4)$ & $152.6(57.7)$ & 0.70 \\
\hline High density lipoprotein (HDL), mg/dL & $50.9(12.1)$ & $53.8(15.3)$ & 0.38 \\
\hline Low density lipoprotein (LDL), mg/dL & $142.3(37.2)$ & $149.3(23.6)$ & 0.34 \\
\hline \multicolumn{4}{|l|}{ Hormone peptides } \\
\hline Insulin, IU/L & $17.3(14.4)$ & $16.0(10.9)$ & 0.66 \\
\hline HOMA-IR index & $4.7(5.3)$ & $4.7(3.8)$ & 0.94 \\
\hline Adiponectin, ug/mL & $12.1(7.7)$ & $14.7(8.7)$ & 0.18 \\
\hline Ghrelin, pg/mL & $555.9(330.4)$ & $523.0(298.5)$ & 0.66 \\
\hline Leptin, ng/mL & $18.5(13.9)$ & $17.3(10.6)$ & 0.67 \\
\hline Apolipoprotein A1, mg/dL & $165.8(29.2)$ & $178.2(38.1)$ & 0.12 \\
\hline Apolipoprotein B100, mg/dL & $117.8(25.6)$ & $120.8(15.2)$ & 0.54 \\
\hline
\end{tabular}

a hospital gown. A wall-mounted stadiometer was used to measure their height to the nearest $0.1 \mathrm{~cm}$, their weight was measured on a calibrated balance beam scale to the nearest $0.1 \mathrm{~kg}$, and BMI was calculated according to the standardized formula: $\mathrm{BMI}=\mathrm{BW} /$ height $^{2}(\mathrm{~kg} /$ $\mathrm{m}^{2}$ ). Waist circumflex (WC) was measured by the mid-way between the lateral lower rib margin and the

Table 2 The composition of green tea extracts

\begin{tabular}{lll}
\hline Component & \% in weight & Daily dose (in mg) \\
\hline EGCG (Epigallocatechin gallate) & 57.12 & 856.8 \\
ECG (Epicatechingallate) & 15.74 & 236.1 \\
EGC (Epigallocatechin) & 7.70 & 115.5 \\
EC (Epicatechin) & 4.80 & 71.9 \\
GCG (Gallocatechingallate) & 4.25 & 63.7 \\
GC (Gallocatechin) & $<0.07$ & $<1.05$ \\
Caffeine & $<0.07$ & $<1.05$ \\
Cellulose & 10.3 & 155.0
\end{tabular}

HOMA-IR = insulin [mIU/L] $\times$ glucose $[\mathrm{mmol} / \mathrm{L}] / 22.5$, and values exceeding 2.25 would be considered as insulin resistance

HOMA-IR index = insulin $(\mu \mathrm{U} / \mathrm{mL}) \times$ glucose $(\mathrm{mmol} / \mathrm{L}) / 22.5$

Glucose $1 \mathrm{mg} / \mathrm{dL}=0.0555 \mathrm{mmol} / \mathrm{L}$ (http://www.endmemo.com/medical/ unitconvert/Glucose.php) iliac crest. The demographic data was collected simultaneously.

\section{Obesity-related hormone peptides}

The obesity-related hormone peptides, including leptin, insulin, ghrelin, adiponectin, apolipoprotein (Apo) A1 and apolipoprotein B100 [7-35] were measured by collecting blood samples in the morning after fasting for 8-9 h. After blood was drawn and centrifuged at $4{ }^{\circ} \mathrm{C}$, a milliliter of aliquot serum was added to the samples and then quick-frozen at $-80{ }^{\circ} \mathrm{C}$ for subsequent radioimmunoassay concentration analysis. The leptin was measured by Millipore Human Leptin assay kit (Millipore, St. Charles, MO, USA), using the $\mathrm{I}^{125}$-labled human leptin antiserum with a sensitivity of $0.5 \mathrm{ng} / \mathrm{ml}$ for a $100-\mu \mathrm{L}$ sample. The ghrelin and adiponectin were identified by the same process as for leptin, with the only difference that $\mathrm{I}^{125}$-labled antibodies were specific to ghrelin or adiponectin, using Ghrelin, and Adiponectin RIA kits (Millipore, St. Charles) with the sensitivity of $93 \mathrm{pg} / \mathrm{ml}$ and $1 \mathrm{ng} / \mathrm{ml}$, respectively. The levels of insulin in serum were determined using BioSource INS-IRMA Kits (BioSource Europe S.A., Nivelles, Belgium). The respective coefficients of variation were $3.1 \%$ for 
intra-assay and $4.9 \%$ for inter-assay. The parameter of sensitivity was $0.5 \mathrm{ng} / \mathrm{ml}$. It was reported that a differentiation exceeding $10 \%$ coefficients of variation was found between replicated results of the sample. The homeostasis model assessment of insulin resistance index (HOMA-IR), used to evaluate level of insulin resistance, was calculated with the following formula: HOMA-IR = insulin $[\mathrm{mIU} / \mathrm{L}] \times$ glucose $[\mathrm{mmol} / \mathrm{L}] / 22.5$. Insulin resistance was indicated when HOMA-IR values exceeded 2.25. The Apo AI and Apo B-100 levels of participants were detected by Immunoturbidimetric assay (K-assay, Kamiya Biomedical Company, Seattle, USA).

\section{EGCG dose analysis}

The sample was extracted by sonication with $100 \mathrm{ml}$ of $50 \%$ methanol for $10 \mathrm{~min}$, and $2 \mathrm{ml}$ of the extract was centrifuged at 10,000 rpm (Eppendorf Centrifuge 5402, MI, USA) for another $10 \mathrm{~min}$. After filtrating the supernatant with a $0.22-\mu \mathrm{m}$ syringe filter (Millipore, Bedford, MA, USA) $20 \mu \mathrm{l}$ of the filtrate was injected into the High Performance Liquid Chromatography (HPLC) system. HPLC analysis used in this study was performed by a Hitachi 7000 series module equipped with a photodiode array detector and the wavelength was set at $273 \mathrm{~nm}$. Catechin, epicatechin and EGCG were separated individually from the extract using a Merck Purospher STAR C-18 $\left(50^{*} 4.6 \mathrm{~mm}\right.$. i.d., $\left.5 \mu \mathrm{m}\right)$. The flow rate of the mobile phase was $0.8 \mathrm{ml} / \mathrm{min}$. All samples were analyzed at room temperature $\left(25 \pm 1{ }^{\circ} \mathrm{C}\right)$.

\section{Statistical analysis}

All the data was analyzed using SPSS software (version 16, Chicago, IL). Student $t$-test was employed to examine the main outcomes, demographic data, and other measurements. Paired $t$-tests were utilized to examine differences of subjects within groups at 0 to 6 weeks in stage 1 and weeks 8 to 14 in stage 2 . All $p$ values were two-tailed and the $\alpha$ level of significance was set at 0.05 .

\section{Results}

Among all the data shown in Table 3, most of the anthropometric data such as weight, body mass index, $\mathrm{WC}$, and waist hip ratio were not significantly different between treatments in stages 1 and 2, by both paired or non-paired $t$-test. Only the HC of Group B significantly decreased from $100.5 \mathrm{~cm}$ on the 56th day to $98.9 \mathrm{~cm}$ on the 98 th day in stage 2 , with the reduction rate at $1.6 \%$.

In stage 1, fasting blood sugar and plasma lipoproteins of Group A did not change significantly. In contrast, fasting blood sugar and adiponectin of Group B significantly decreased on the 42th day of treatment, only by the paired $t$-test. The fasting blood sugar means (SD) of Group B reduced from $114.9 \mathrm{mg} / \mathrm{dL}$ (49.0) to $106.4 \mathrm{mg} /$ $\mathrm{dL}$ (28.6) on the 42th day of treatment. There was a significant $7.4 \%$ reduction in fasting blood sugar ( $p=0.047$, paired t-test) in Group B as compared with that of Group A (2.3\%). Except adiponectin, the hormone peptides of Group A and Group B were not significantly different after treatments in this stage. The means (SD) of adiponectin increased from $14.7 \mu \mathrm{g} / \mathrm{mL}$ (8.7) to $16.1 \mu \mathrm{g} /$ $\mathrm{mL}$ (8.3) on the 42th day of treatment, showing a $9.5 \%$ increase which was higher than that of Group A (9.9\%).

In stage 2, Group A was given placebo and Group B received GTE. Reductions were observed in several biomarkers, i.e. LDL, adiponectin, ghrelin and apolipoprotein B100. In Group B, LDL at this stage showed a 5.9\% reduction, means (SD) decreasing from $145.5 \mathrm{mg} / \mathrm{dL}$ (29.4) on the 56 th day to $136.9 \mathrm{mg} / \mathrm{dL}$ (26.2) on the 98th day $(p=0.01)$. The adiponectin of Group A showed an $18.8 \%$ reduction from $13.3 \mu \mathrm{g} / \mathrm{mL}$ (8.6 for SD) on the 56th day to $10.8 \mu \mathrm{g} / \mathrm{mL}$ (4.8 for SD) on the 98th day, as compared to a $7.6 \%$ reduction in Group B $(p=0.02)$. In Groups A and Group B, ghrelin level significantly decreased, showing a reduction of $19.7 \%(p=0.01$, paired $t$-test) and $17.7 \%(p=0.01)$, respectively. There was also a 5.0\% reduction in Apolipoprotein B100 for Group B, from $125.1 \mathrm{mg} / \mathrm{dL}$ (21.8 for SD) to $118.9 \mathrm{mg} / \mathrm{dL}$ (19.1 for SD) $(p=0.02)$.

The double-blind, placebo-controlled, cross-over design study showed that there were no statistical difference in the levels of BMI, fasting blood sugar, total cholesterol, triglyceride, high density lipoprotein, adiponectin and ghrelin etc. between the GTE and placebo groups after treatments. However, it especially showed a significant $25.7 \%$ increase in leptin and $4.8 \%$ decrease in LDL-C levels over the trial period, with the $p$ values being 0.046 and 0.048 respectively (Table 4 ) compared to the control group.

Green tea consumption in the form of EGCG, GTE or catechins by subjects with high BMI may decrease body weight, BMI, waist and hip circumference and improve blood lipid profile, glucose homeostasis as well as decrease inflammatory markers. However, the results are not consistent by showing either an improvement or no effect.

\section{Discussion}

There have been many studies that reported on the beneficial effects of GTE on a person's health including weight loss. Our study showed significant increase in leptin and decrease in LDL-C levels in patients who received GTE treatment.

With an increase in obesity prevalence, many alternative treatments for weight control are developed [34]. Studies argued that GTE appeared to have anti-obesity and anti-diabetic effects. However, in this double-blind, placebo-controlled, cross-over design study, the results revealed that green tea extract with a high dose of EGCG was not able to produce a significant decrease in 
Table 3 Measurements at different stages and the days after intervention

\begin{tabular}{|c|c|c|c|c|c|}
\hline Measurements & Stage & Days & $\begin{array}{l}\text { Group A } \\
n=36 \\
\text { mean (SD) }\end{array}$ & $\begin{array}{l}\text { Group B } \\
n=37 \\
\text { mean (SD) }\end{array}$ & $p$-value \\
\hline \multirow[t]{2}{*}{ Weight, kg } & 1 & 0 & $70.6(11.4)$ & $67.8(9.1)$ & 0.25 \\
\hline & 1 & 42 & $70.4(11.5)$ & $67.7(9.2)$ & 0.28 \\
\hline \multirow[t]{3}{*}{$p$-value for paired $t$-test } & & & 0.45 & 0.58 & \\
\hline & 2 & 56 & $70.5(11.2)$ & $68.0(9.3)$ & 0.30 \\
\hline & 2 & 98 & $68.4(15.5)$ & $67.6(9.3)$ & 0.80 \\
\hline$p$-value for paired $t$-test & & & 0.27 & 0.13 & \\
\hline \multirow[t]{2}{*}{ Body Mass Index, kg/m² } & 1 & 0 & $29.1(4.9)$ & $27.9(3.3)$ & 0.26 \\
\hline & 1 & 42 & $28.9(4.9)$ & $27.9(3.3)$ & 0.29 \\
\hline \multirow[t]{3}{*}{$p$-value for paired $t$-test } & & & 0.44 & 0.60 & \\
\hline & 2 & 56 & $29.0(4.8)$ & $28.0(3.4)$ & 0.32 \\
\hline & 2 & 98 & $28.1(6.6)$ & $27.8(3.4)$ & 0.81 \\
\hline$p$-value for paired $t$-test & & & 0.27 & 0.11 & \\
\hline \multirow[t]{2}{*}{ Waist Circumference (WC), cm } & 1 & 0 & $89.7(12.4)$ & $86.6(9.5)$ & 0.23 \\
\hline & 1 & 42 & $90.0(11.3)$ & $87.2(8.2)$ & 0.22 \\
\hline \multirow[t]{3}{*}{$p$-value for paired $t$-test } & & & 0.66 & 0.40 & \\
\hline & 2 & 56 & $89.2(10.7)$ & $87.8(9.6)$ & 0.55 \\
\hline & 2 & 98 & $89.8(10.1)$ & $87.4(9.5)$ & 0.29 \\
\hline$p$-value for paired $t$-test & & & 0.27 & 0.57 & \\
\hline \multirow[t]{2}{*}{ Hip Circumference $(\mathrm{HC}), \mathrm{cm}$} & 1 & 0 & $100.8(8.8)$ & $99.5(6.6)$ & 0.48 \\
\hline & 1 & 42 & $101.1(8.7)$ & $99.5(6.6)$ & 0.38 \\
\hline \multirow[t]{3}{*}{$p$-value for paired $t$-test } & & & 0.57 & 0.93 & \\
\hline & 2 & 56 & $100.7(8.7)$ & $100.5(7.2)$ & 0.91 \\
\hline & 2 & 98 & $101.0(9.0)$ & $98.9(7.6)$ & 0.29 \\
\hline$p$-value for paired $t$-test & & & 0.38 & 0.01 & \\
\hline \multirow[t]{2}{*}{ Waist hip ratio } & 1 & 0 & $0.89(0.07)$ & $0.87(0.06)$ & 0.24 \\
\hline & 1 & 42 & $0.89(0.06)$ & $0.88(0.06)$ & 0.36 \\
\hline \multirow[t]{3}{*}{$p$-value for paired $t$-test } & & & 0.78 & 0.28 & \\
\hline & 2 & 56 & $0.88(0.05)$ & $0.87(0.06)$ & 0.41 \\
\hline & 2 & 98 & $0.89(0.05)$ & $0.88(0.06)$ & 0.65 \\
\hline$p$-value for paired $t$-test & & & 0.44 & 0.21 & \\
\hline \multirow[t]{2}{*}{ Fasting blood sugar, mg/dL } & 1 & 0 & $105.2(23.8)$ & $114.9(49.0)$ & 0.29 \\
\hline & 1 & 42 & $102.8(18.7)$ & $106.4(28.6)$ & 0.53 \\
\hline \multirow[t]{3}{*}{$p$-value for paired $t$-test } & & & 0.37 & 0.047 & \\
\hline & 2 & 56 & $103.4(22.0)$ & $103.1(22.0)$ & 0.96 \\
\hline & 2 & 98 & $103.1(26.2)$ & $106.2(26.9)$ & 0.62 \\
\hline$p$-value for paired $t$-test & & & 0.90 & 0.23 & \\
\hline \multirow[t]{2}{*}{ Total cholesterol, mg/dL } & 1 & 0 & $218.8(42.4)$ & $229.6(30.3)$ & 0.21 \\
\hline & 1 & 42 & $213.3(41.4)$ & $226.2(25.9)$ & 0.12 \\
\hline \multirow[t]{3}{*}{$p$-value for paired $t$-test } & & & 0.13 & 0.47 & \\
\hline & 2 & 56 & $220.3(46.3)$ & $224.8(31.9)$ & 0.62 \\
\hline & 2 & 98 & $220.3(40.3)$ & $217.6(27.7)$ & 0.74 \\
\hline$p$-value for paired $t$-test & & & 1.00 & 0.05 & \\
\hline
\end{tabular}


Table 3 Measurements at different stages and the days after intervention (Continued)

\begin{tabular}{|c|c|c|c|c|c|}
\hline Measurements & Stage & Days & $\begin{array}{l}\text { Group A } \\
n=36 \\
\text { mean (SD) }\end{array}$ & $\begin{array}{l}\text { Group B } \\
n=37 \\
\text { mean (SD) }\end{array}$ & $p$-value \\
\hline \multirow[t]{2}{*}{ Triglyceride, mg/dL } & 1 & 0 & $147.4(57.4)$ & $152.6(57.7)$ & 0.70 \\
\hline & 1 & 42 & $144.4(59.7)$ & $152.5(66.1)$ & 0.58 \\
\hline \multirow[t]{3}{*}{$p$-value for paired $t$-test } & & & 0.72 & 1.00 & \\
\hline & 2 & 56 & $134.9(53.4)$ & $138.5(49.5)$ & 0.77 \\
\hline & 2 & 98 & $142.8(47.3)$ & $150.4(53.3)$ & 0.52 \\
\hline$p$-value for paired $t$-test & & & 0.32 & 0.10 & \\
\hline \multirow[t]{2}{*}{ High density lipoprotein (HDL), mg/dL } & 1 & 0 & $50.9(12.1)$ & $53.8(15.3)$ & 0.38 \\
\hline & 1 & 42 & $50.1(10.5)$ & $53.6(12.1)$ & 0.19 \\
\hline \multirow[t]{3}{*}{$p$-value for paired $t$-test } & & & 0.39 & 0.88 & \\
\hline & 2 & 56 & $50.0(11.2)$ & $53.6(12.5)$ & 0.19 \\
\hline & 2 & 98 & $50.4(11.2)$ & $53.7(12.5)$ & 0.25 \\
\hline$p$-value for paired $t$-test & & & 0.64 & 0.98 & \\
\hline \multirow[t]{2}{*}{ Low density lipoprotein (LDL), mg/dL } & 1 & 0 & $142.3(37.2)$ & $149.3(23.6)$ & 0.34 \\
\hline & 1 & 42 & $135.3(39.8)$ & $145.8(22.8)$ & 0.17 \\
\hline \multirow[t]{3}{*}{$p$-value for paired $t$-test } & & & 0.05 & 0.38 & \\
\hline & 2 & 56 & $142.7(41.6)$ & $145.5(29.4)$ & 0.74 \\
\hline & 2 & 98 & $141.9(34.4)$ & $136.9(26.2)$ & 0.49 \\
\hline$p$-value for paired $t$-test & & & 0.84 & 0.01 & \\
\hline \multirow[t]{2}{*}{ Insulin, IU/L } & 1 & 0 & $17.3(14.4)$ & $16.0(10.9)$ & 0.66 \\
\hline & 1 & 42 & $13.9(6.6)$ & $15.9(9.3)$ & 0.31 \\
\hline \multirow[t]{3}{*}{$p$-value for paired $t$-test } & & & 0.14 & 0.97 & \\
\hline & 2 & 56 & $15.3(6.2)$ & $15.2(9.4)$ & 0.94 \\
\hline & 2 & 98 & $16.3(7.7)$ & $16.5(14.3)$ & 0.95 \\
\hline$p$-value for paired $t$-test & & & 0.30 & 0.38 & \\
\hline \multirow[t]{2}{*}{ HOMA-IR index } & 1 & 0 & $4.7(5.3)$ & $4.7(3.8)$ & 0.94 \\
\hline & 1 & 42 & $3.4(1.6)$ & $4.3(3.4)$ & 0.19 \\
\hline \multirow[t]{3}{*}{$p$-value for paired $t$-test } & & & 0.17 & 0.63 & \\
\hline & 2 & 56 & $3.8(1.7)$ & $3.9(2.4)$ & 0.89 \\
\hline & 2 & 98 & $4.2(2.3)$ & $4.5(4.4)$ & 0.72 \\
\hline$p$-value for paired $t$-test & & & 0.26 & 0.25 & \\
\hline \multirow[t]{2}{*}{ Adiponectin, ug/mL } & 1 & 0 & $12.1(7.7)$ & $14.7(8.7)$ & 0.18 \\
\hline & 1 & 42 & $13.3(6.0)$ & $16.1(8.3)$ & 0.10 \\
\hline \multirow[t]{3}{*}{$p$-value for paired $t$-test } & & & 0.14 & 0.02 & \\
\hline & 2 & 56 & $13.3(8.6)$ & $15.8(7.9)$ & 0.20 \\
\hline & 2 & 98 & $10.8(4.8)$ & $14.6(9.0)$ & 0.03 \\
\hline$p$-value for paired $t$-test & & & 0.02 & 0.15 & \\
\hline \multirow[t]{2}{*}{ Ghrelin, pg/mL } & 1 & 0 & $555.9(330.4)$ & $523.0(298.5)$ & 0.66 \\
\hline & 1 & 42 & $481.9(173.0)$ & $531.5(225.8)$ & 0.30 \\
\hline \multirow[t]{3}{*}{$p$-value for paired $t$-test } & & & 0.20 & 0.87 & \\
\hline & 2 & 56 & $427.9(146.6)$ & $450.1(149.3)$ & 0.52 \\
\hline & 2 & 98 & $357.5(90.4)$ & 370.5 (119.8) & 0.60 \\
\hline
\end{tabular}

$p$-value for paired $t$-test 
Table 3 Measurements at different stages and the days after intervention (Continued)

\begin{tabular}{|c|c|c|c|c|c|}
\hline Measurements & Stage & Days & $\begin{array}{l}\text { Group A } \\
n=36 \\
\text { mean (SD) }\end{array}$ & $\begin{array}{l}\text { Group B } \\
n=37 \\
\text { mean (SD) }\end{array}$ & $p$-value \\
\hline \multirow[t]{2}{*}{ Leptin, ng/mL } & 1 & 0 & $18.5(13.9)$ & $17.3(10.6)$ & 0.68 \\
\hline & 1 & 42 & $19.3(14.1)$ & $15.1(7.2)$ & 0.12 \\
\hline \multirow[t]{3}{*}{$p$-value for paired $t$-test } & & & 0.75 & 0.15 & \\
\hline & 2 & 56 & $15.1(9.4)$ & $14.1(7.1)$ & 0.60 \\
\hline & 2 & 98 & $14.4(10.2)$ & $14.5(7.7)$ & 0.97 \\
\hline$p$-value for paired $t$-test & & & 0.57 & 0.72 & \\
\hline \multirow[t]{2}{*}{ Apolipoprotein A1, mg/dL } & 1 & 0 & $165.8(29.2)$ & $178.2(38.1)$ & 0.12 \\
\hline & 1 & 42 & $166.0(33.7)$ & $171.6(34.4)$ & 0.48 \\
\hline \multirow[t]{3}{*}{$p$-value for paired $t$-test } & & & 0.97 & 0.16 & \\
\hline & 2 & 56 & $175.6(34.5)$ & $184.8(35.6)$ & 0.27 \\
\hline & 2 & 98 & $174.1(36.8)$ & $180.5(34.2)$ & 0.44 \\
\hline$p$-value for paired $t$-test & & & 0.69 & 0.36 & \\
\hline \multirow[t]{2}{*}{ Apolipoprotein B100, mg/dL } & 1 & 0 & $117.8(25.6)$ & $120.8(15.2)$ & 0.54 \\
\hline & 1 & 42 & $117.5(28.2)$ & $120.4(18.3)$ & 0.61 \\
\hline \multirow[t]{3}{*}{$p$-value for paired $t$-test } & & & 0.91 & 0.88 & \\
\hline & 2 & 56 & $123.8(31.4)$ & $125.1(21.8)$ & 0.85 \\
\hline & 2 & 98 & $121.9(27.7)$ & $118.9(19.1)$ & 0.58 \\
\hline$p$-value for paired $t$-test & & & 0.55 & 0.02 & \\
\hline
\end{tabular}

Table 4 Outcome of epigallocatechin gallate and cellulose after 6 weeks of treatment

\begin{tabular}{llll}
\hline$n=73$ & Green tea extract & cellulose \\
Cases reductions, \% & mean (SD) & mean (SD) & $p$ value \\
\hline Weight, $\mathrm{kg}$ & $-0.5(2.5)$ & $-1.5(10.7)$ & 0.41 \\
Body Mass Index, $\mathrm{kg} / \mathrm{m}^{2}$ & $-0.5(2.5)$ & $-1.5(10.7)$ & 0.41 \\
Waist Circumference (WC), cm & $0.2(5.0)$ & $0.2(2.5)$ & 0.36 \\
Hip Circumference (HC), cm & $-0.6(3.2)$ & $0.7(4.1)$ & 0.11 \\
Waist hip ratio & $0.8(5.0)$ & $-2.0(12.9)$ & 0.91 \\
Fasting blood sugar, mg/dL & $1.2(11.9)$ & $0.3(12.3)$ & 0.12 \\
Total cholesterol, mg/dL & $-2.3(9.7)$ & $9.8(41.0)$ & 0.15 \\
Triglyceride, mg/dL & $7.5(32.6)$ & $1.8(14.6)$ & 0.71 \\
High density lipoprotein, mg/dL & $-0.1(10.2)$ & $0.5(17.3)$ & 0.35 \\
Low density lipoprotein, mg/dL & $-4.8(14.6)$ & $11.8(47.0)$ & $\mathbf{0 . 0 4 8}$ \\
Insulin, IU/L & $4.5(47.4)$ & $9.3(42.7)$ & 0.35 \\
HOMA-IR index & $7.1(54.4)$ & $6.9(42.2)$ & 0.78 \\
Adiponectin, ug/mL & $15.2(68.8)$ & $1.4(39.7)$ & 0.38 \\
Ghrelin, pg/mL & $-6.0(39.0)$ & $-1.02(44.9)$ & 0.26 \\
Leptin, $\mathrm{ng} / \mathrm{mL}$ & $25.7(103.8)$ & $-1.3(14.4)$ & $\mathbf{0 . 0 4 6}$ \\
Apolipoprotein A1, mg/dL & $0.4(20.5)$ & $0.2(14.8)$ & 0.55 \\
Apolipoprotein B100, mg/dL & $-2.0(12.6)$ & 0.35 \\
\hline
\end{tabular}

(+ means increase and - means reduction) 
body weight, BMI or fasting blood sugar levels in obese Taiwanese women within the trial period although in many human studies there have been reported decrease in body weight and body fat [35].

GTE has shown to increase fat oxidation and energy expenditure due to its high concentration of EGCG [36]. EGCG inhibits catechol-o-methyltransferase (COMT) which is an enzyme that causes the degradation of norepinephrine. This in turns results in increased lipolysis and fat oxidation [37]. It has been suggested that the COMT single nucleotide polymorphism (SNP rs4680) is very common in Asians and alters sensitivity to EGCG, which leads to a greater energy expenditure and body fat loss due to more effective supplementation. Therefore it is important to consider the ethnicity when conducting this kind of study as better results are obtained amongst the Asian population in comparison to Caucasians [38].

Furthermore, leptin has a role in regulating lipid metabolism as it stimulates fatty acid oxidation and decreases triglyceride stores within fat cells in the liver as well as inhibiting lipogenesis and stimulates lipolysis in fat cells [40].

Once leptin is released by the adipose tissue, it is secreted into the bloodstream and circulated in proportion to body fat mass [39]. It provides the brain with information about the status of the body's energy stores. There are several factors that influence the regulation of circulating leptin levels including food intake and glucose uptake which increase the levels of circulating leptin while exercise and increased age decrease the levels of circulating leptin [41].

Leptin crosses the blood-brain barrier and activates the leptin receptor, which causes an inhibitory effect on associated insulin stimulated metabolic pathways. Therefore treating adipocytes with leptin reduces insulin stimulation of carbohydrate and lipid metabolism as well as insulin stimulation of protein synthesis. Previous studies have found that leptin suppresses the LDL receptors (LDL-R) through the repressed expression of the SREBP2, which is a transcription factor of LDLR gene [39].

The LDLR gene is responsible for the production of LDL-R, which binds LDL particles. LDL primarily carry cholesterol in the blood. LDL-R binds to LDL circulating in the bloodstream and transports them into the cell. The LDL are broken down and the cholesterol is released. LDL-R are critical in regulating the amount of cholesterol in the blood [42].

Our study showed that there was a significant decrease in LDL levels after GTE consumption. It is consistent with a previous study that showed green tea decreasing absorption of lipids and proteins in the intestine and also activating the pathway to decrease gluconeogenesis and fatty acid synthesis [43]. It is, however, suggested that disruption of leptin receptors have no significant impact on target organs because its main effect is on the brain that then has the effect on glucose and lipid metabolism [44] and thus this study suggests that GTE is the main cause of the lowering of LDL levels.

There has been similar studies done in the past to determine whether green tea extracts have been advantageous in improving various biochemical markers related to obesity but this is one of the few studies that is designed with a crossover. This allows for accurate comparisons of biochemical markers within the same individuals during stages 1 and 2. Each individual serves as his or her own control, therefore decreasing the variability between the individuals. It is therefore not necessary to make any adjustments to variables such as dietary intake, levels of physical activity or post-menopausal changes. At the commencement of the trial, individuals were also instructed to follow their previous dietary habits throughout the course of the study as stated in the Method section. Another advantage of this crossover study is that it requires a smaller sample size compared to previous studies such as Samavat et al. [45] and Tian C et al. [46] having 936 and 19,471 participants respectively. With a smaller sample size, there runs a risk of participants withdrawing leaving little data to be analyzed.

This study presents with several limitations. Firstly, the short duration of the study might not have allowed sufficient time for significant changes to take place. When compared with previous studies such as Samavat et al. [45] and Tian $C$ et al. [46] running over the duration of years. In retrospect, a study by $\mathrm{Li}$ [47] suggests that noticeable effects of tea only occur after 8 or more weeks of intervention. Even though participants were only exposed to GTE for 6 weeks, it caused a noticeable change in leptin and LDL levels. Secondly, the gender and ethnical limitations render this study not applicable to all persons of the general population.

\section{Conclusion}

This study shows that green tea extract effectively increases leptin and reduces LDL in women after 6 weeks of treatment even though there were no significant changes in other biochemical markers related to overweight such as total cholesterol, triglyceride, and BMI.

\section{Additional files}

Additional file 1: CONSORT Flow Diagram. (DOC $53 \mathrm{~kb}$ )

Additional file 2: This is the raw data that was gathered in the clinical trial and was used to establish the data base of this study. (DOC $219 \mathrm{~kb}$ )

\section{Abbreviations}

BMI: Body mass index; COMT: Catechol-o-methyltransferase; CVD: Cardiovascular disease; EC: Epicatechin; ECG: Epicatechingallate; EGC: Epigallocatechin; EGCG: Epigallocatechin gallate; GTE: Green tea extract; LDL-C: Lipoproteincholesterol; WHO: World Health Organization 


\section{Acknowledgements}

There are no special acknowledgements that need to be made.

\section{Funding}

This study was financially supported by National Science Council, Taiwan under grant NSC 101-2320-B-010-075. NSC played no role in the design of the study and collection, analysis, and interpretation of data and in writing the manuscript, but had the right to have observers this study.

\section{Availability of data and materials}

The raw data has been uploaded along with the manuscript as (Additional files and 2) or can be obtained by contacting the corresponding author via e-mail. The data has been translated over to English from its original language Mandarin.

\section{Authors' contributions}

Study Design: LHH, CYL, CJH, CHH, Data Collection: LHH, LYW, CJH, Statistical Analysis: LHH, LYW, Data Interpretation: LHH, CYL, LYW, CHH, Manuscript Preparation: $\mathrm{LHH}, \mathrm{CYL}, \mathrm{CH}$, Literature Search: $\mathrm{LHH}, \mathrm{CYL}, \mathrm{CHH}$, Funds Collection: LYW, $\mathrm{CHH}$, All authors have read and approved the final manuscript for publishing.

\section{Ethics approval and consent to participate}

The protocol for this clinical research received ethical approval by the Taipei City Hospital Institutional Review Board on 26 July 2012. The trial was register with ClinicalTrials.gov on 17 April 2014: NCT02116517. All participants gave written informed consent by signing an consent form and had the freedom to withdraw from the study at any time. The study adheres to CONSORT guidelines.

\section{Consent for publication}

No details, images or videos of specific individuals are included in the report therefore no consent for publication needed. (N/A).

\section{Competing interests}

The authors declare that they have no competing interests.

\section{Publisher's Note}

Springer Nature remains neutral with regard to jurisdictional claims in published maps and institutional affiliations.

\section{Author details}

'Institute of Traditional Medicine, National Yang-Ming University, No. 155, Section 2, Linong St, Beitou District, Taipei City, Taiwan112. 'Branch of Linsen, Chinese Medicine, and Kunming, Taipei City Hospital, No. 530, Linsen North Road, Zhongshan District, Taipei City 104, Taiwan. ${ }^{3}$ Department of Endocrinology, Branch of Linsen, Chinese Medicine, and Kunming, Taipei City Hospital, No. 530, Linsen North Road, Zhongshan District, Taipei City 104, Taiwan.

\section{Received: 26 April 2018 Accepted: 18 October 2018}

\section{Published online: 06 November 2018}

\section{References}

1. Malik VS, Willett WC, Hu FB. Global obesity: Trends, risk factors and policy implications. Nat Rev Endocrinol. 2013;9(1):13-27.

2. Finucane MM, Stevens GA, Cowan MJ, Danaei G, Lin JK, Paciorek CJ, Singh GM, Gutierrez HR, Lu Y, Bahalim AN, Farzadfar F, Riley LM, Ezzati M, Global Burden of Metabolic Risk Factors of Chronic Diseases Collaborating, G. National, regional, and global trends in body-mass index since 1980: systematic analysis of health examination surveys and epidemiological studies with 960 country-years and 9.1 million participants. Lancet. 2011; 377(9765):557-67.

3. Huang $\mathrm{LH}$, Liao $\mathrm{YL}, \mathrm{Hsu} \mathrm{CH}$. Waist circumference is a better predictor than body mass index of insulin resistance in type 2 diabetes. Obes Res Clin Pract. 2012:6(4):314-20.

4. Lloyd-Jones D, Adams RJ, Brown TM, et al. Heart disease adn stroke statisticsc-2010 update: a report from the American Heart Association. Circulation. 2010;121:e46-e215

5. Jain KS, Kathiravan MK, Somani RS, Shishoo CJ. The biology and chemistry of hyperlipidemia. Bioorg Med Chem. 2007;15:4674-99.

6. Apovian CM, Gokce N. Obesity and cardiovascular disease. Circulation. 2012 125(9):1178-82.
7. Nikolopoulou A, Kadoglou NP. Obesity and metabolic syndrome as related to cardiovascular disease. Expert Rev CardiovascTher. 2012;10(7):933-9.

8. Gu GL, Xu XL, Yang QY, Zeng RL. Effect of CETP Polymorphism on Atorvastatin Lipid-Regulating Effect and Clinical Prognosis of Patients with Coronary Heart Disease. Med Sci Monit. 2014;20:2824-9.

9. Zamani B, Saatlo BB, Naghavi-Behzad M, Taqizadeh-Jahed M, Alikhah H, Abbasnezhad M. Effects of high versus low-dose atorvastatin on high sensitive C-reactive protein in acute coronary syndrome. Niger Med J. 2014; 55(6):490-4.

10. Lafeber M, Grobbee DE, Schrover IM, Thom S, Webster R, Rodgers A, Visseren FL, Bots ML, Spiering W. Comparison of a morning polypill, evening polypill and individual pills on LDL-cholesterol, ambulatory blood pressure and adherence in high-risk patients; a randomized crossover trial. Int J Cardiol. 2014;181C:193-9

11. Suh Y, Kim BK, Shin DH, Kim JS, Ko YG, Choi D, Jang Y, Hong MK. Impact of statin treatment on strut coverage after drug-eluting stent implantation. Yonsei Med J. 2015:56(1):45-52.

12. Pastori D, Polimeni L, Baratta F, Pani A, Del Ben M, Angelico F. The efficacy and safety of statins for the treatment of non-alcoholic fatty liver disease. Dig Liver Dis. 2015;47(1):4-11.

13. Kalantari S, Naghipour M. Statin therapy and hepatotoxicity: Appraisal of the safety profile of atorvastatin in hyperlipidemic patients. Adv Biomed Res. 2014;3:168.

14. Sun L, Lee DE, Tan WJ, Ranawana DV, Quek YC, Goh HJ, Henry CJ. Glycaemic index and glycaemic load of selected popular foods consumed in Southeast Asia. Br J Nutr. 2015;113(5):843-8.

15. Keske MA, Ng HL, Premilovac D, Rattigan S, Kim JA, Munir K, Yang P, Quon MJ. Vascular and metabolic actions of the green tea polyphenol epigallocatechin gallate. Curr Med Chem. 2015;22(1):59-69.

16. Bajerska J, Mildner-Szkudlarz S, Walkowiak J. Effects of rye bread enriched with green tea extract on weight maintenance and the characteristics of metabolic syndrome following weight loss: a pilot study. J Med Food. 2015; 18(6):698-705

17. Yarmolinsky J, Gon G, Edwards P. Effect of tea on blood pressure for secondary prevention of cardiovascular disease: a systematic review and meta-analysis of randomized controlled trials. Nutr Rev. 2015;73(4):236-46.

18. Sikand G, Kris-Etherton P, Boulos NM. Impact of functional foods on prevention of cardiovascular disease and diabetes. Curr Cardiol Rep. 2015; 17(6):39.

19. Kim HM, Kim J. The effects of green tea on obesity and type 2 diabetes. Diabetes Metab J. 2013:37:173-5.

20. Dulloo AG, Duret C, Rohrer D, Girardier L, Mensi N, Fathi M, Chantre P, Vandermander J. Efficacy of a green tea extract rich in catechin polyphenols and caffeine in increasing 24-h energy expenditure and fat oxidation in humans. Am J Clin Nutr. 1999:70:1040-5.

21. Diepvens K, Westerterp KR, Westererp-Plantenga MS. Obesity and thermogenesis related to the consumption of caffeine, ephedrine, capsaicin and green tea. Am J Phys Regul Integr Comp Phys. 2007;292:R77-85.

22. Tian C, Ye X, Zhang R, Long J, Ren W, Ding S, Liao D, Jin X, Wu H, Xu S, Ying C. Green tea polyphenols reduced fat deposits in high fat-fed rats via erk1/2-PPARgamma-adiponectin pathway. PLoS One. 2013:8:e53796.

23. Goto T, Saito Y, Morikawa K, Kanamaru Y, Nagaoka S. Epigallocatechin gallate changes mRNA expression level of genes involved in cholesterol metabolism in hepatocytes. Br J Nutr. 2012;107:769-73.

24. Li Y, Zhao S, Zhang W, Zhao P, He B, Wu N, Han P. Epigallocatechin-3-Ogallate (EGCG) attenuates FFAs-induced peripheral insulin resistance through AMPK pathway and insulin signaling pathway in vivo. Diabetes Res Clin Pract. 2011;93:205-14.

25. Sone T, Kuriyama S, Nakaya N, Hozawa A, Shimazu T, Nomura K, Rikimaru S, Tsuji I. Randomized controlled trial for an effect of catechin-enriched green tea consumption on adiponectin and cardiovascular disease risk factors. Food Nutr Res. 2011:55. https://doi.org/10.3402/fnr.v55i0.8326. Epub 2011 Dec 1

26. Hursel R, Viechtbauer W, Dulloo AG, Tremblay A, Tappy L, Rumpler W, WesterterpPlantenga MS. The effects of catechin rich teas and caffeine on energy expenditure and fat oxidation: a meta-analysis. Obes Rev. 2011;12:e573-81.

27. Khan N, Mukhtar H. Tea polyphenols for health promotion. Life Sci. 2007:81: 519-33.

28. Bose M, Lambert JD, Ju J, Reuhl KR, Shapses SA, Yang CS. The major green tea polyphenol, Epigallocatechin-3-gallate, inhibits obesity, metabolic syndrome, and fatty liver disease in high-fat-fed mice. J Nutr. 2008:138: 1677-83. 
29. Wolfram S, Wang Y, Thielecke F. Anti-obesity effects of green tea: from bedside to bench. Mol Nutr Food Res. 2006;50(2):176-87.

30. Basu A, Sanchez K, Leyva MJ, Wu M, Betts NM, Aston CE, Lyons TJ. Green tea supplementation affects body weight, lipids, and lipid peroxidation in obese subjects with metabolic syndrome. J Am Coll Nutr. 2010;29(1):31-40.

31. Fujiwara T, Yoshioka S, Yosioka T, Ushiyama I, Horikoshi H. Characterization of new oral antidiabetic agent CS-045:studies in KK and ob/obmice and Zucker fatty rats. Diabetes. 1988;37:1549-58.

32. Rocha A, Bolin AP, Cardoso CA, Otton R. Green tea extract activated AMPK and ameliorates white adipose tissue metabolic dysfunction induced by obesity. Eur J Nutr. 2015;55:2231-44.

33. Krotkiewski M, Bjorntorp P, Sjostrom L, Smith U. Impact of obesity on metabolism in men and women. J Clin Invest. 1983;73:1150-62.

34. Hsu C, Hwang K, Chao C, Lin J, Kao S, Chou P. Effects of electroacupunture in reducing weight and waist circumference in obese women: a randomized crossover trial. Int J Obes. 2005;29(11):1379-84.

35. Hsu C, Tsai T, Kao Y, Hwang K, Tseng T, Chou P. Effect of green tea extract on obese women: a randomized, double-blind, placebo-controlled clinical trial. Clin Nutr. 2008;27:363-70.

36. Liu C, Huang C, Huang L, Chen I, Chiu J, Hsu C. Effects of green tea extract on insulin resistance and glucagon like peptide 1 in patients with type 2 diabetes and lipid abnormalities: a randomized, double-blinded, and placebo-controlled trial. PLoS One. 9(3):e91163. https://doi.org/10.1371/ journal.pone.0091163.

37. Most J, van Can J, van Dijk J, Goossens G, Jocken J, Hospers J, Bendik I, Blaak E. A 3-day EGCG-supplementation reduces interstitial lactate concentration in skeletal muscle of overweight subjects. Sci Rep. 2015;5: 17896. https://doi.org/10.1038/srep178996.

38. Noguiera de Amorim LM, Vaz SR, Ceserio G, Coelho A, Botelho P. Effect of green tea extract on bone mass and body composition in individuals with diabetes. J Funct Foods. 2018:40:589-94.

39. Yadav N, Arjuman A, Chandra N. Role of leptin on expression of low density lipoprotein receptor. Indian J Med Res. 2014;140(4):524-30.

40. Lee Y, Yu X, Gonzales F, et al. PPARa is necessary for the lipopenic action of hyperleptinemia on white adipose and liver tissue. Proc Natl Acad Sci U S A. 2002;99(18):11848-53. https://doi.org/10.1073/pnas.182420899.

41. Klok M, Jakobsdottir S, Drent ML. The role of leptin and gherlin in the regulation of food intake and body weight in humans: a review. Obes Rev. 2007:8(1):21-34.

42. Genetics Home Referance [Internet]. LDLR ene. NHI; [updated 2018 Feb; cited 2018 Feb 27]. Available from: http://ghr.nlm.nih.gov/gene/LDLR\#.

43. Yang CS, Zhang J, Zhang L, Huang J, Wang Y. Mechanisms of body weight reduction and metabolic syndrome alleviation by tea. Mol Nutr Food Res. 2016:60(1):160-74. https://doi.org/10.1002/mnfr.201500428.

44. Park H-K, Ahima RS. Physiology of leptin: energy homeostasis, neuroendocrine function and metabolism. Metab Clin Exp. 2015;64(1):24-34. https://doi.org/10.1016/j.metabol.2014.08.004.

45. Samavat H, Newman A, Wang R, Yuan J, Wu A, Kurzer M. Effect of green tea catechin extract on serum lipids in postmenopausal women: a randomized, placebo-controlled clinical trial. Am J Clin Nutr. 2016;104:1671-82.

46. Tian C, Huang Q, Yang L, Legare S, Angileri F, Yang H, et al. Green tea consumption is associated with reduced incident CHD and improved CHDrelated biomarkers in the Dongfeng-Tongji cohort. Sci Rep. 2016;6:24353. https://doi.org/10.1038/srep24353.

47. Yi L, Wang C, Huai Q, Guo F, Liu L, Feng R, Sun C. Effects of tea or tea extract on metabolic profiles in patients with type 2 diabetes mellitus: a meta-analysis of ten randomized controlled trials. Diabetes Metab Res Rev. 2016;32:2-10.

Ready to submit your research? Choose BMC and benefit from:

- fast, convenient online submission

- thorough peer review by experienced researchers in your field

- rapid publication on acceptance

- support for research data, including large and complex data types

- gold Open Access which fosters wider collaboration and increased citations

- maximum visibility for your research: over $100 \mathrm{M}$ website views per year

At BMC, research is always in progress.

Learn more biomedcentral.com/submissions 